\title{
Is the insect apocalypse upon us? How to find out
}

by Montgomery, G.A., Dunn, R.R., Fox, R., Jongejans, E., Leather, S.R., Saunders, M.E., Shortall, C.R., Tingley, M.W. and Wagner, D.L.

Copyright, publisher and additional Information: This is the author accepted manuscript. The final published version (version of record) is available online via Elsevier.

This version is made available under the CC-BY-ND-NC licence:

https://creativecommons.org/licenses/by-nc-nd/4.0/legalcode

Please refer to any applicable terms of use of the publisher

DOI: https://doi.org/10.1016/j.biocon.2019.108327

Harper Adams University

Montgomery, G.A., Dunn, R.R., Fox, R., Jongejans, E., Leather, S.R., Saunders, M.E., Shortall, C.R., Tingley, M.W. and Wagner, D.L. 2019. Is the insect apocalypse upon us? How to find out. Biological Conservation.

22 November 2019 
KEYWORDS: Insect declines, biodiversity crisis, biomass, monitoring, entomology ABSTRACT

In recent decades, entomologists have documented alarming declines in occurrence, taxonomic richness, and geographic range of insects around the world. Additionally, some recent studies have reported that insect abundance and biomass, often of common species, are rapidly declining, which has led some to dub the phenomenon an "Insect Apocalypse". Recent reports are sufficiently robust to justify immediate actions to protect insect biodiversity worldwide. We caution, however, that we do not yet have the data to assess large-scale spatial patterns in the severity of insect trends. Most documented collapses are from geographically restricted studies and, alone, do not allow us to draw conclusions about insect declines on continental or global scales, especially with regards to future projections of total insect biomass, abundance, and extinction. There are many challenges to understanding insect declines: only a small fraction of insect species have had any substantial population monitoring, millions of species remain unstudied, and most of the long-term population data for insects come from human-dominated landscapes in western and northern Europe. But there are still concrete steps we can take to improve our understanding of potential declines. Here, we review the challenges scientists face in documenting insect population and diversity trends, including communicating their findings, and recommend research approaches needed to address these challenges.

\section{INTRODUCTION}

Declines of insect abundance, biomass, and range are being reported worldwide, from the arctic to the tropics, across insect orders, and from a spectrum of ecological guilds (e.g., Fox 2013, Hallmann et al. 2017, Loboda et al. 2018, Lister \& Garcia 2018, and reviews by Sanchez-Bayo \& Wyckhuys 2019, Wagner 2017, 2019b). Though fewer than 100 insect species are documented as extinct (IUCN 2019), more recent extinctions have assuredly occurred on islands and deforested tropical regions. One important aspect of many recent studies is the decline of formerly common species, not just rare taxa (Conrad et al. 2006, Van Dyck et al. 2009, Fox et al. 2015), with the realization that such losses likely come with changes to ecosystem connectivity and function (Gaston \& Fuller 2007, Dirzo et al. 2014). Some studies have reported dramatic declines: Hallmann et al. (2017) found a 75\% decrease in flying-insect biomass over a threedecade period from 63 preserves in northwestern Germany. Declines are also reported from many western and northern European countries, representing a suite of different insect orders (e.g., Conrad et al. 2006, Shortall et al. 2009, Schuch et al. 2012, Van Strien et al. 2019, Hallmann et al. 2019; see also reviews by Sanchez-Bayo \& Wyckhuys 2019, Wagner 2017 , $2019 b$ ). Two of the studies that drew worldwide media attention (Lister \& Garcia 2018, SanchezBayo \& Wyckhuys 2019) not only ignited discussion of insect declines among scientists and lay people alike, but also received substantial criticism - their methods, results, and extrapolations are much contested (Komonen et al. 2019, Mupepele et al. 2019, Simmons et al. 2019, Thomas 
et al. 2019, Wagner 2019a, Willig et al. 2019; see Saunders 2019 for a review of the datasets informing this discussion).

Many insect taxa are unequivocally in decline across many regions of the planet, and we know enough to take conservation action (Basset \& Lamarre 2019, Janzen \& Hallwachs 2019, Forister et al. 2019). However, important aspects of the insect decline phenomenon remain largely unknown. Most importantly, we need to understand how quickly populations are trending upward or downward. Annual declines of 1-2\% for species in densely human-populated areas are unfortunate but relatively unsurprising, while $>3 \%$ annual declines in areas far removed from most human activities would be stunning. Failure to make such distinctions can lead to untenable extrapolations, e.g., that $40 \%$ of the world's insects will be extinct in a few decades, as posited in Sanchez-Bayo \& Wyckhuys (2019). Next, are the rates of population change of insects roughly on par with those of plants, birds, and mammals, as found generally by Dirzo et al. (2014)? If so, then the apocalypse is one suffered by all species. An answer to this question could also point to the drivers. If insects are declining at rates appreciably faster than vertebrates and plants in the same regions, it may be prudent to focus research on stressors like that especially impact insects (e.g., insecticide use), or it may be an indication of what is to come for other taxa. Finally, with so few data from outside Europe, it is difficult to gauge how widespread the phenomenon is, especially in the tropics (Basset \& Lamarre 2019, Janzen \& Hallwachs 2019), where more 85\% of all insect species occur (Stork 2018), and in temperate regions of the southern hemisphere. Many studies show that there are winners as well as losers in recent insect biodiversity change (Brooks et al. 2012; Boyes et al 2019) and that net loss of insect abundance/biomass has not been reported from all study locations (Shortall et al. 2009; Valtonen et al. 2017; Herrera 2019). Overall, although progress is being made, attempts to answer questions regarding the magnitude, and in many cases even the existence, of insect declines face many challenges. Here, we outline these challenges, but focus on research recommendations, from increased monitoring, to community science and pleas for more rigorous methodologies and meta-analyses. We also touch on matters of unexplored data streams, reporting bias, and funding needs.

\section{CHALLENGES}

\section{The Insect Side}

The greatest challenge to studying insect population trends, be it declines in diversity, abundance, range, occurrence or other metrics, is the paucity of baseline data (Cardoso et al. 2011, Eisenhauer et al. 2019, Wagner 2017, 2019b, Cardoso \& Leather 2019): we lack robust records of past insect populations and diversity. Traditionally, entomological collections have been focused on documenting species diversity rather than abundance, often for a narrow range of taxa, and as such, yield little information about population numbers and survey effort, rendering many historical collection events essentially non-replicable. The geographic distribution of haphazardly distributed baseline data is also a problem - those data that do exist come mostly from "anthroposcapes," or human-altered ecosystems. While these data are useful 
insect populations in areas with modest human activity and wildlands (Wagner 2019b). The temporal distribution of available baseline datasets is also an issue. Many of the baseline data that do exist post-date the onset of purported drivers of insect declines, for example, the UK Butterfly Monitoring Scheme, a flagship long-term insect monitoring effort, began in 1976, after agricultural intensification was well underway (Pollard \& Yates 1994).

85

Additionally, large natural fluctuations in invertebrate populations from year to year, and sometimes even within a single year, make drawing conclusions from demographic studies of insects challenging (Fox et al. 2019). This large interannual population variation is dependent on many intrinsic and extrinsic factors (Hanski 1990), including myriad natural enemies (Turchin et al. 1999) and the vagaries of weather (Wolda 1983, Nelson et al. 2013). This is especially problematic for the interpretation of "snapshot" surveys where population data from one period are compared with population data from another period, without data from intervening years (Habel et al. 2019).

Entomologists and those reliant on sound insect identifications also face an enormous taxonomic impediment (Samways 1993, Habel et al. 2019), especially in tropical regions. It is difficult to know what we are losing when $80 \%$ of insect species (representing, conservatively, four million species) remain undescribed and their natural histories unknown (Stork 2018). High insect species diversity compounds this problem; identification of every insect even in a small sample in an area with low alpha diversity can be time- or cost-prohibitive. Declines in insect identification expertise further degrade the ability to determine biodiversity and population trends for most insect lineages (Hopkins \& Freckleton 2002); growing sources of identification knowledge through community science, machine learning, and genetic barcoding are helpful, but cannot compensate the continuing loss of professional taxonomist expertise. Using indicator taxa can be an effective approach to sidestep aspects of the taxonomic impediment problem but doing so often results in inadequate knowledge and compromised measures of interest (McGeoch 1998, Thomas 2005).

There are many consequences of this shortfall of insect biodiversity knowledge, when combined with a general lack of baseline population data. One illustration can be seen in the number of insects with global conservation statuses evaluated by the International Union for Conservation of Nature: only 8,355 insect species have been evaluated, and 2,104 of those are "data deficient" (IUCN 2019), out of an estimated 5.5 million insect species worldwide (Stork 2018).

\section{The Human Side}

Scientific, public and political interest in insect population declines and conservation is encouraging and has led to new research programs, redoubled interest in sampling methodologies, catalyzed interest in analyses of historical data sets, led to biodiversity-friendly government initiatives, and increased funding for the study of insects. Several high-profile studies finding large declines in insect populations or biomass have spurred massive media attention and generated unprecedented public interest in insects and their ecosystem services. Unfortunately, some media reports of insect declines have made extrapolations that have leapt beyond credible evidence, though there are examples of more balanced coverage (e.g., Yong 
2019). Exaggerated claims can sometimes trigger complex feedback loops between scientists, institutions, media and the public (Ransohoff \& Ransohoff 2001, Bubela 2006, Caulfield \& Condit 2012). To avoid such claims from being made, it is incumbent upon scientists to continue presenting thoughtful, critical assessments; the risks of false positives are high. Because global insect populations have such importance, and also because of the enormous data gaps and potential biases, it is especially important to commit to elevated standards of study design, evidence, and communication.

Human psychology also poses challenges for understanding the insect decline phenomenon, and we should be aware of human tendencies that affect this field. For example, humans tend to view insects as one homogeneous group, which masks the complex and variable effects occurring across taxa and guilds (Habel et al. 2019). Older people recall seeing more moths in headlights ("the moth snowstorm"), summer nights filled with fireflies, and splatted insects on their windshields. Such anecdotes are valuable, but only rarely can be substantiated. On the other hand, younger people may not notice what has been lost as a result of shifting baseline syndrome (Pauly 1995, Soga \& Gaston 2018). However, it is also true that a generational shift in where people live has also occurred, with broad shifts toward cities and hence the experience of the subset of species that thrive in cities. Confirmation bias, the tendency to interpret data to support existing hypotheses (Nickerson 1988), could creep into experimental design and analyses, especially in ecological studies where many effects interact weakly. Publication bias is also no doubt at play, where statistically significant results are selected for publication more often than studies with non-significant results (Rosenthal 1979). How large a problem might it be that studies documenting losses are more likely to be written, reviewed, and accepted for publication than studies showing little change? Indeed, studies of insects in general are less likely to be published than studies of other taxonomic groups (Leather 2009), another form of publication bias. There is also a tendency for the most extreme results to be published and cited (Ioannidis 2005 ) - this may be especially relevant for a topical issue like insect declines. While most scientists are already aware of these issues, it is important to regularly remind ourselves of them.

\section{RESEARCH RECOMMENDATIONS}

Determining the scale and severity of declines in insect diversity, abundance, and range must be among the most urgent global research, conservation, and legislative priorities going forward. But what research will be most effective? Entomologists have unique opportunities in this moment of heightened public awareness.

\section{Monitoring}

First, we need to establish insect monitoring networks on a global scale. By using repeatable sampling methods, new monitoring programs can augment pre-existing ones, and help determine population trends, identify drivers of trends, and serve to engage the public through community science (Lewandowski \& Oberhauser 2017). We advocate for large-scale programs to monitor abundances, biomass, and species diversity using standardized, effort-based methods such as Malaise trapping, pitfall trapping, suction trapping, light trapping, count surveying, and new 
160

161

162

163

164

165

166

167

168

169

170

171

172

173

174

175

176

177

178

179

180

181

182

183

184

185

186

187

188

189

190

191

192

193

194

195

196

197

198

199

200

methods such as the modified window traps of Knuff et al. (2019) or smart insect cameras (Hogeweg et al. 2019). Although biomass is an imperfect estimator of diversity because it can be sensitive to changes in abundances of large species (e.g., Shortall et al. 2009), it is a valuable metric from the ecosystem perspective. Determining biomass trends also does not require finescale taxonomic knowledge, which is often limited to individuals with specialized training. We advocate this approach with necessary caveats; it is often impractical to attempt monitoring all insect species from any community with appreciable diversity (though meta-barcoding and other genetic approaches can help).

Long-term monitoring should consider the relative economic and ecological costs and benefits; although regular lethal trapping may not have major impacts on insect communities (Gezon et al. 2015), the economic costs of sampling and identification of large volumes of many taxa may be prohibitive (Tepedino et al. 2015; Drinkwater et al. 2019). Better-known taxa like butterflies, macromoths, orthopterans, and some bees and beetles can serve as indicator or substitute species for other insect groups, but only when carefully validated (Henry et al. 2019).

Effective long-term monitoring takes many forms, including complex spatial designs with many observers and single-observer designs with temporally intensive data from fewer sites (Pocock et al. 2015). Continuous, or at least multi-year, time-series are especially valuable for insects, where year-to-year population variation can be high. Although longitudinal time-series (e.g., Wepprich et al. 2019) provide better inferential power, "snapshot" surveys are useful for taxa or regions limited by a lack of continuous historical data, if scientists control for variation in effort and changes in methods - whether through strong data filtering or direct statistical modeling (Tingley 2017) - and can replicate previously conducted surveys on a broad geographic scale.

Though existing long-term monitoring programs are relatively rare, programs that do exist provide invaluable data and can be used as models for new monitoring efforts. A non-exhaustive list of such programs include the Wijster Biological Station pitfall program (NL; Den Boer \& van Dijk 1994), the Rothamsted Insect Survey (UK; Storkey et al. 2016), the Krefield Entomological Society surveys (DE; Hallmann et al. 2017), the United Kingdom, Dutch \& Catalan Butterfly Monitoring Schemes (UK; Pollard \& Yates 1994, NL; Van Swaay et al. 1997, ES; Melero et al. 2016), midwestern butterfly surveys (US; Swengel et al. 2011, Wepprich et al. 2019), and the Shapiro butterfly surveys (US; Forister et al. 2011). Collectively, these programs form the basis for a large part of what we know about long-term diversity and population trends in insects - the next step is expanding and complementing these schemes on a global scale, while continuing to support existing programs.

\section{Surveying across space}

Surveys across light pollution, agricultural intensification, pesticide use, plant invasion, urban heat island, human density, or other gradients could provide insight into what factors are contributing to insect declines and their relative importance. There is an urgent need to gather demographic data from tropical sites - while not wholly surprising, it is ironic that we know the least about the Earth's most species rich and ecologically diverse entomofaunas (Stork 2018). In addition, surveys that substitute space for time can serve as an imperfect substitute for baseline data. This survey strategy is commonly used in ecology when time-series data are lacking (Blois 
et al. 2013) and can prove particularly powerful when tested against experimental data and, for the subset of sites for which they are available, time-series data (Lahr et al. 2018).

\section{Making time-series data available}

We also need to make baseline data more open and accessible. Continuous or nearly continuous time-series of insect abundance and diversity have been collected by observers outside of insect conservation and ecology circles. For example, changes in lady beetle populations have been monitored using control plots at experimental farms (Alyokhin \& Sewell 2004). Vertebrate ecologists studying insectivores that also collect insect (prey) abundance data have the potential to contribute much to our knowledge of insect population trends (e.g., Harris et al. 2019).

Data collected by agricultural and silvicultural monitoring, land-management agencies, insect collectors, and nature enthusiasts can all be useful. These datasets, like datasets from traditional ecological sources, should be made available and posted to online repositories like Dryad (datadryad.org), BioTIME (biotime.st-andrews.ac.uk; Dornelas et al. 2018), or the Global Biodiversity Information Facility (gbif.org) when possible. We recognize that there are social and financial barriers to contributing data sets to online repositories that still need to be addressed, and care needs to be taken to protect the intellectual property rights of ongoing longterm surveys to ensure their continuity (Pearce-Higgins et al. 2018).

\section{Community science}

Some of the best long-term monitoring data comes from community or citizen scientists. The biomass declines reported by Hallmann et. al. (2017) in Germany are based on the work of the Krefield Entomological Society, an organization of knowledgeable entomologists, most of which commit their free time to insect research. Beyond already existing community science efforts, the current moment is also an opportunity to reach new audiences with a message of insect conservation on a global scale (see Pocock et al. 2018). Concerned community scientists can be recruited to re-sample "snapshot" surveys on a large geographic scale. Similarly, enlisting school classrooms to participate in insect monitoring can provide useful data (e.g., the School Malaise Trap Program in Canada: Steinke et al. 2017, and Saunders et al. 2018). Live pitfall and LED UV-light traps are inexpensive to set up and monitor and can mitigate ethical concerns sometimes associated with specimen collecting, especially by the public. Taxa such as caterpillars, larger beetles, and wasps can be imaged (and identified) with cell phones, offering myriad possibilities. School monitoring programs also have the potential to be expanded to larger geographic scales.

Such community science efforts simultaneously serve to educate, raise awareness about the importance of insects, and provide opportunities for invertebrate conservation (Lewandowski \& Oberhauser 2017). Error and bias due to variation in the expertise of the participants is a recognized issue (Gardiner et al. 2012) and designing protocols that account for or minimize this is important (see Dennis et al. 2017); training projects such as BioLinks (https://www.fscbiodiversity.uk/projects/biolinks) can play invaluable roles. There are many successful insect-related community science projects that collect useful data on insect abundance, diversity, or distribution that can serve as models. Examples include The Monarch 

Larva Monitoring Project, National Moth Recording Scheme, Caterpillars Count, Bumble Bee Watch, Lost Lady Bug Project, Firefly Watch, Wild Bee Garden Count, Western Monarch Thanksgiving Count, Australia's Wild Pollinator Count, UK Pollinator Monitoring Scheme, iNaturalist.org, and BugGuide.net.

\section{Reporting and synthesizing results}

Once insect trend data have been collected, they need to be shared, and well-designed insect demography studies should be published or otherwise made available. To combat publication bias, researchers, reviewers, and journal editors alike need to publish reports of increasing and stable trends, in addition to documenting declines. Reports of where insects are not declining are as important as reports of where they are declining, since this heterogeneity can help elucidate key threats. Unbiased reporting will also reduce systematic biases in the literature, which is helpful for researchers performing systematic reviews and meta-analyses. These forms of evidence synthesis can effectively provide a means of evaluating the scale and severity of insect declines and their potential drivers when they follow question formulation tools like PICO (Richardson et al. 1995) and reporting guidelines like ROSES (Haddaway et al. 2018). We recommend projects such as the EntoGEM systematic mapping project (Grames et al. 2019; https://entogem.github.io), a community-driven effort to assimilate global literature and data sets relevant to insect population and diversity trends.

\section{Under-exploited datasets}

Beyond these steps, however, complementary approaches are needed to fully evaluate the mechanisms, pattern, and consequences of insect declines, especially to provide alternative baseline data. For example, NEXRAD is a network of weather radars in the United States that are used to monitor birds (Dokter et al. 2018); data from these radars could also provide estimates of aerial insect biomass flows over the last 25 years (Hu et al. 2016). The use of museum collections to estimate insect trends (e.g., Cameron et al. 2011, Bartomeus et al. 2013, Boyle et al. 2019) is becoming more powerful with new statistical methods. Caution is required when using data that were not collected for this purpose (e.g., see Wepprich 2019), including spatiotemporal bias (Ries et al. 2019), and abundance trends do not always correlate positively with occurrence (range) data (Dennis et al. 2019). However, museum collections can be used to infer trends and drivers of trends (e.g., Scheper et al. 2014, Meineke et al. 2019), and effort data can sometimes be extracted from species-list length in a time or place (Van Strien et al. 2013). Continued digitization efforts (e.g., iDigBio, LepNet, SCAN) are necessary to bring collection data to bear on the issue of insect declines, since current numbers of digitized specimens are not enough to draw conclusions about trends in many cases (Ries et al. 2019). Stored samples from monitoring projects are also available and have been utilized to some extent (Shortall et al. 2009, Hallmann et al. 2017) — most are available for further work. In some cases, data for insectivorous taxa may exist where baseline data for insects do not, perhaps allowing inferences about insect diversity and population levels (English et al. 2018, Wagner 2019b). Such insectivorous taxa can also provide insect data directly, through DNA sequencing diet samples or feces (e.g., Krauel et al. 2018). Entomologists should also think broadly and creatively about new technologies and "Big Data" streams that could be used to study insects, from passive 
acoustic monitoring (Zilli et al. 2014), smart insect cameras, and eDNA (Mächler et al. 2014) to LIDAR (Simonson et al. 2014), and social media (Alvaro et al. 2015).

\section{FUNDING}

Few of these research priorities will be feasible without funding. There needs to be a recognition by research funding agencies, foundations, and individuals that entomological survey and monitoring work should receive a step-change in funding. Funding should more closely reflect abundance, diversity, and ecological importance of taxa, not their perceived charisma (Clark \& May 2002). Crowdsourcing may draw in some funds, but what is required is stable, substantial funding that will allow existing and future international collaborations to flourish. For this to happen, we need to convince funders, and society, to support insect conservation as much as insect control. Long-term monitoring studies can be unappealing to funders and yet are the main lens through which we understand the rapid changes in biological systems; in this way they are akin to public health surveillance, essential and yet radically underfunded compared to studies of medical interventions.

\section{CONCLUSION}

Insects are in trouble, and we must take conservation actions now, rather than wait for biologists to provide exhaustive demographic data, measure all drivers, and attempt to quantify population trends across thousands of individual lineages. But the many data gaps presently in the insect decline literature do matter, and it remains to be seen if some recent alarming results are indicative of global-scale insect declines that would trigger losses of ecosystem function. The drivers of declines are many, from habitat loss, agricultural intensification, and climate change, to invasive species, pesticides, and light pollution, but much remains unknown, including the scope and severity of insect declines. Despite the challenges faced by researchers studying trends in insect diversity and demography, it is urgent that we fill these crucial data gaps and use rigorous science to do so. It is time to get to work.

\section{ACKNOWLEDGEMENTS}

\section{REFERENCES}

Alvaro, N., M. Conway, S. Doan, C. Lofi, J. Overington, and N. Collier. 2015. Crowdsourcing Twitter annotations to identify first-hand experiences of prescription drug use. Journal of Biomedical Informatics 58:280-287.

Alyokhin, A., \& Sewell, G. (2004). Changes in a lady beetle community following the establishment of three alien species. Biological Invasions, 6(4), 463-471. 
Basset, Y., \& G. P. Lamarre (2019). Toward a world that values insects. Science 364(6447): 1230-1231.

Bartomeus, I, Ascher JS, Gibbs J, Danforth BN, Wagner DL, et al. 2013. Historical changes in northeastern United States bee pollinators related to shared ecological traits. Proceedings of the National Academy of Sciences 110:4656-4660.

Blois, J. L., J. W. Williams, M. C. Fitzpatrick, S. T. Jackson, and S. Ferrier. 2013. Space can substitute for time in predicting climate-change effects on biodiversity. Proceedings of the National Academy of Sciences 110:9374-9379.

Boyes, D. H., Fox, R., Shortall, C. R., \& Whittaker, R. J. (2019). Bucking the trend: the diversity of Anthropocene 'winners' among British moths. Frontiers of Biogeography (in press).

Boyle, J. H., H. J. Dalgleish, and J. R. Puzey. 2019. Monarch butterfly and milkweed declines substantially predate the use of genetically modified crops. Proceedings of the National Academy of Sciences 116:3006-3011.

Brooks, D. R., Bater, J. E., Clark, S. J., Monteith, D. T., Andrews, C., Corbett, S. J., Bfeaumont D. A. \& Chapman, J. W. (2012). Large carabid beetle declines in a United Kingdom monitoring network increases evidence for a widespread loss in insect biodiversity. Journal of Applied Ecology 49(5): 1009-1019.

Bubela, T. 2006. Science communication in transition: genomics hype, public engagement, education and commercialization pressures. Clinical Genetics 70:445-450.

Cameron, S. A., J. D. Lozier, J. P. Strange, J. B. Koch, N. Cordes, L. F. Solter, and T. L. Griswold. 2011. Patterns of widespread decline in North American bumble bees. Proceedings of the National Academy of Sciences 108:662-667.

Cardoso P, Erwin TL, Borges PAV \& New TR (2011) The seven impediments in invertebrate conservation and how to overcome them. Biological Conservation 144: $2647-2655$.

Cardoso, P., \& Leather, S. R. (2019). Predicting a global insect apocalypse. Insect Conservation and Diversity 12(4) 263-267.

Caulfield, T., and C. Condit. 2012. Science and the Sources of Hype. Public Health Genomics 15:209-217.

Clark, J. A., \& May, R. M. (2002). Taxonomic bias in conservation research. Science 297(5579), 191-192. 
Conrad, K. F., M. S. Warren, R. Fox, M. S. Parsons, and I. P. Woiwod. 2006. Rapid declines of common, widespread British moths provide evidence of an insect biodiversity crisis. Biological Conservation 132:279-291.

Den Boer PJ \& van Dijk T.S. (1994) Carabid beetles in a changing environment. Wageningen Agricultural University Papers, Wageningen, the Netherlands, 94:1-30.

Dennis, E. B., T. M. Brereton, B. J. T. Morgan, R. Fox, C. R. Shortall, T. Prescott, and S. Foster. 2019. Trends and indicators for quantifying moth abundance and occupancy in Scotland. Journal of Insect Conservation 23:369-380.

Dennis, E. B., Morgan, B. J., Brereton, T. M., Roy, D. B., \& Fox, R. (2017). Using citizen science butterfly counts to predict species population trends. Conservation Biology, 31(6), 1350-1361.

Dirzo, R., H. S. Young, M. Galetti, G. Ceballos, N. J. Isaac, and B. Collen. 2014. Defaunation in the Anthropocene. Science. 345:401-406.

Dokter, A. M., A. Farnsworth, D. Fink, V. Ruiz-Gutierrez, W. M. Hochachka, F. A. L. Sorte, O. J. Robinson, K. V. Rosenberg, and S. Kelling. 2018. Seasonal abundance and survival of North America's migratory avifauna determined by weather radar. Nature Ecology \& Evolution 2:1603.

Dornelas M, Antão LH, Moyes F, Bates, AE, Magurran, AE, et al. 2018. BioTIME: A database of biodiversity time series for the Anthropocene. Global Ecol Biogeogr; 27:760786.

Drinkwater, E., Robinson, E. J., \& Hart, A. G. (2019). Keeping invertebrate research ethical in a landscape of shifting public opinion. Methods in Ecology and Evolution 10:1265-1273.

Eisenhauer N, Bonn A \& Guerra CA (2019) Recognizing the quiet extinction of invertebrates. Nature Communications 10(1): 50.

English, P. A., D. J. Green, and J. J. Nocera. 2018. Stable Isotopes from Museum Specimens May Provide Evidence of Long-Term Change in the Trophic Ecology of a Migratory Aerial Insectivore. Frontiers in Ecology and Evolution 6.

Fleishman, E., \& Murphy, D. D. (2009). A realistic assessment of the indicator potential of butterflies and other charismatic taxonomic groups. Conservation Biology, 23(5), 1109-1116. 
Forister, M. L., J. P. Jahner, K. L. Casner, J. S. Wilson, and A. M. Shapiro. 2011. The race is not to the swift: Long-term data reveal pervasive declines in California's lowelevation butterfly fauna. Ecology 92:2222-2235.

Forister, M. L., Pelton, E. M., \& Black, S. H. (2019). Declines in insect abundance and diversity: We know enough to act now. Conservation Science and Practice, e80.

Fox, R. 2013. The decline of moths in Great Britain: a review of possible causes: The decline of moths in Great Britain. Insect Conservation and Diversity 6:5-19.

Fox, R., C. A. Harrower, J. R. Bell, C. R. Shortall, I. Middlebrook, and R. J. Wilson. 2019. Insect population trends and the IUCN Red List process. Journal of Insect Conservation 23: 269-278.

Fox, R., T. M. Brereton, J. Asher, T. A. August, M. S. Botham, et al. 2015. The state of the UK's Butterflies 2015. Wareham, Engl.: Butterfly Conservation and the Centre for Ecology \& Hydrology.

Gardiner, M. M., L. L. Allee, P. M. Brown, J. E. Losey, H. E. Roy, and R. R. Smyth. 2012. Lessons from lady beetles: accuracy of monitoring data from US and UK citizenscience programs. Frontiers in Ecology and the Environment 10:471-476.

Gaston, K. J., and R. A. Fuller. 2007. Biodiversity and extinction: losing the common and the widespread. Prog. Phys. Geogr. Earth Environ. 31:213-25.

Gaston, K. J., and R. A. Fuller. 2008. Commonness, population depletion and conservation biology. Trends Ecol. Evol. 23:14-19.

Gezon, Z. J., Wyman, E. S., Ascher, J. S., Inouye, D. W., \& Irwin, R. E. (2015). The effect of repeated, lethal sampling on wild bee abundance and diversity. Methods in Ecology and Evolution, 6(9), 1044-1054.

Grames E. M., G. A. Montgomery, N. R. Haddaway, L. V. Dicks, C. S. Elphick, T. A. Matson, S. Nakagawa, M. E. Saunders, M. W. Tingley, T. E. White, P. Woodcock, and D. L. Wagner. 2019. Trends in global insect abundance and biodiversity: A communitydriven systematic map protocol. OSF Registries https://doi.org/10.17605/OSF.IO/Q63UY

Habel, J. C., M. J. Samways, M. J., \& T. Schmitt. 2019. Mitigating the precipitous decline of terrestrial European insects: Requirements for a new strategy. Biodiversity and Conservation, 28(6), 1343-1360.

Haddaway, N. R., B. Macura, P. Whaley, and A. S. Pullin. 2018. ROSES RepOrting standards for Systematic Evidence Syntheses: pro forma, flow-diagram and descriptive summary of the plan and conduct of environmental systematic reviews and systematic maps. Environmental Evidence 7. 
Hallmann, C. A., M. Sorg, E. Jongejans, H. Siepel, N. Hofland, H. Schwan, W. Stenmans, A. Müller, H. Sumser, T. Hörren, D. Goulson, and H. de Kroon. 2017. More than 75 percent decline over 27 years in total flying insect biomass in protected areas. PLOS ONE 12:e0185809.

Hallmann, C. A., Zeegers, T., Klink, R., Vermeulen, R., Wielink, P., Spijkers, H., Deijk, J., Steenis, W. and Jongejans, E. (2019), Declining abundance of beetles, moths and caddisflies in the Netherlands. Insect Conservation and Diversity. doi:10.1111/icad.12377

Hanski I. (1990) Density dependence, regulation and variability in animal populations. Phil Trans R Soc B 330:141-150.

Harris, J.E., Rodenhouse, N.L., Holmes, R.T. 2019. Decline in beetle abundance and diversity in an intact temperate forest linked to climate warming. Biological Conservation. In press.

Henry, E., Brammer-Robbins, E., Aschehoug, E., \& Haddad, N. (2019). Do substitute species help or hinder endangered species management? Biological Conservation, 232, 127-130.

Herrera, C. M. (2019). Complex long-term dynamics of pollinator abundance in undisturbed Mediterranean montane habitats over two decades. Ecological Monographs: 89(1): e01338.

Hogeweg L, Zeegers, T., Katramados, I., Jongejans, E., 2019. Smart Insect Cameras. Biodiversity Information Science \& Standards 3, e39241. https://doi.org/10.3897/biss.3.39241

Hopkins, G. W., \& Freckleton, R. P. (2002). Declines in the numbers of amateur and professional taxonomists: implications for conservation. In Animal Conservation Forum (Vol. 5, No. 3, pp. 245-249). Cambridge University Press.

Hu, G., Lim, K. S., Horvitz, N., Clark, S. J., Reynolds, D. R., Sapir, N., \& Chapman, J. W. (2016). Mass seasonal bioflows of high-flying insect migrants. Science, 354(6319), 1584-1587.

Ioannidis, J. P. A. 2005. Why Most Published Research Findings Are False. PLOS Medicine 2:e124.

IUCN 2019. The IUCN Red List of Threatened Species. Version 2019-2. http://www.iucnredlist.org. Downloaded on 20 July 2019.

Janzen, D. H., \& Hallwachs, W. (2019). Perspective: Where might be many tropical insects? Biological Conservation, 233:102-108. 
Knuff, A. K., Winiger, N., Klein, A. M., Segelbacher, G., \& Staab, M. Optimising sampling of flying insects using a modified window trap. Methods in Ecology and Evolution 00:1-6.

Komonen, A., P. Halme, and J. S Kotiaho. 2019. Alarmist by bad design: Strongly popularized unsubstantiated claims undermine credibility of conservation science. Rethinking Ecology 4:17-19.

Krauel, J. J., Brown, V. A., Westbrook, J. K., \& McCracken, G. F. (2018). Predator-prey interaction reveals local effects of high-altitude insect migration. Oecologia, 186(1), 4958.

Lahr, E. C., Dunn, R. R., \& Frank, S. D. (2018). Getting ahead of the curve: cities as surrogates for global change. Proceedings of the Royal Society B: Biological Sciences 285(1882), 20180643.

Leather, S. R. 2009. Taxonomic chauvinism threatens the future of entomology. The Biologist 56:4.

Lewandowski, E. J., and K. S. Oberhauser. 2017. Butterfly citizen scientists in the United States increase their engagement in conservation. Biological Conservation 208:106-112.

Lister, B. C., and A. Garcia. 2018. Climate-driven declines in arthropod abundance restructure a rainforest food web. Proceedings of the National Academy of Sciences 115:E10397-E10406.

Loboda, S., J. Savage, C. M. Buddle, N. M. Schmidt, and T. T. Høye. 2018. Declining diversity and abundance of High Arctic fly assemblages over two decades of rapid climate warming. Ecography 41:265-277.

Mächler, E., K. Deiner, P. Steinmann, and F. Altermatt. 2014. Utility of environmental DNA for monitoring rare and indicator macroinvertebrate species. Freshwater Science $33: 1174-1183$.

McGeoch, M. A. 1998. The selection, testing and application of terrestrial insects as bioindicators. Biological Reviews 73:181-201.

Meineke, E. K., Davies, T. J., Daru, B. H., \& Davis, C. C. (2018). Biological collections for understanding biodiversity in the Anthropocene. Philosophical Transactions of the Royal Society B: Biological Sciences 374:20170386.

Melero, Y., C. Stefanescu, and J. Pino. 2016. General declines in Mediterranean butterflies over the last two decades are modulated by species traits. Biological Conservation 201:336-342. 
Mupepele, A. C., Bruelheide, H., Dauber, J., Krüß, A., Potthast, T., Wägele, W., \& Klein, A. M. (2019). Insect decline and their drivers: Unsupported conclusions in a poorly performed meta-analysis on trends-a critique of Sánchez-Bayo and Wyckhuys (2019). Basic and Applied Ecology 37, 20-23.

Nelson, W. A., O. N. Bjornstad, and T. Yamanaka. 2013. Recurrent Insect Outbreaks Caused by Temperature-Driven Changes in System Stability. Science 341:796-799.

Nickerson, R. S. (1998). Confirmation bias: A ubiquitous phenomenon in many guises. Review of General Psychology, 2(2), 175-220.

Pauly, D. 1995. Anecdotes and the shifting baseline syndrome of fisheries. Trends in Ecology \& Evolution 10:430.

Pocock, M. J. O., S. E. Newson, I. G. Henderson, J. Peyton, W. J. Sutherland, D. G. Noble, S. G. Ball, B. C. Beckmann, J. Biggs, T. Brereton, D. J. Bullock, S. T. Buckland, M. Edwards, M. A. Eaton, M. C. Harvey, M. O. Hill, M. Horlock, D. S. Hubble, A. M. Julian, E. C. Mackey, D. J. Mann, M. J. Marshall, J. M. Medlock, E. M. O’Mahony, M. Pacheco, K. Porter, S. Prentice, D. A. Procter, H. E. Roy, S. E. Southway, C. R. Shortall, A. J. A. Stewart, D. E. Wembridge, M. A. Wright, and D. B. Roy. 2015. Developing and enhancing biodiversity monitoring programmes: a collaborative assessment of priorities. Journal of Applied Ecology 52:686-695.

Pearce-Higgins JW, Baillie SR, Boughey K, Bourn NAD, Foppen RPB, Gillings S, Gregory RD, Hunt T, Jiguet F, Lehikoinen A, Musgrove AJ, Robinson RA, Roy DB, Siriwardena GM, Walker KJ, Wilson JD (2018) Overcoming the challenges of public data archiving for citizen science biodiversity recording and monitoring schemes. Journal of Applied Ecology 55:2544-2551.

Pocock MJO, Chandler M, Bonney R, Thornhill I, Albin A, August T, Bachman S, Brown PMJ, Gasparini Fernandes Cunha D, Grez A, Jackson C, Peters M, Romer Rabarijaon N, Roy HE, Zaviezo T \& Danielsen F (2018) A vision for global biodiversity monitoring with citizen science. Advances in Ecological Research 59, 169-223.

Pollard, E., \& Yates, T. J. (1994). Monitoring butterflies for ecology and conservation: the British butterfly monitoring scheme. London: Chapman \& Hall.

Powney, G. D., C. Carvell, M. Edwards, R. K. A. Morris, H. E. Roy, B. A. Woodcock, and N. J. B. Isaac. 2019. Widespread losses of pollinating insects in Britain. Nature Communications 10.

Ransohoff, D. F., and R. M. Ransohoff. 2001. Sensationalism in the media: when scientists and journalists may be complicit collaborators. Effective Clinical Practice, 4:185-188. 
Richardson, W. S., Wilson, M. C., Nishikawa, J., \& Hayward, R. S. (1995). The wellbuilt clinical question: a key to evidence-based decisions. ACP Journal Club, 123(3), A12-3.

Ries, L., Zipkin, E. F., \& Guralnick, R. P. (2019). Tracking trends in monarch abundance over the 20th century is currently impossible using museum records. Proceedings of the National Academy of Sciences, 116(28), 13745-13748.

Rosenthal, R. 1979. The file drawer problem and tolerance for null results. Psychological Bulletin 86:638-641.

Samways, M. J. 1993. Insects in biodiversity conservation: some perspectives and directives. Biodiversity \& Conservation 2:258-282.

Sánchez-Bayo, F., and K. A. G. Wyckhuys. 2019. Worldwide decline of the entomofauna: A review of its drivers. Biological Conservation 232:8-27.

Saunders, M. E., E. Roger, W. L. Geary, F. Meredith, D. J. Welbourne, A. Bako, E. Canavan, F. Herro, C. Herron, O. Hung, M. Kunstler, J. Lin, N. Ludlow, M. Paton, S. Salt, T. Simpson, A. Wang, N. Zimmerman, K. B. Drews, H. F. Dawson, L. W. J. Martin, J. B. Sutton, C. C. Webber, A. L. Ritchie, L. D. Berns, B. A. Winch, H. R. Reeves, E. C. McLennan, J. M. Gardner, C. G. Butler, E. I. Sutton, M. M. Couttie, J. B. Hildebrand, I. A. Blackney, J. A. Forsyth, D. M. Keating, and A. T. Moles. 2018. Citizen science in schools: Engaging students in research on urban habitat for pollinators. Austral Ecology 43:635-642.

Saunders, M. E., Janes, J. K., \& O'Hanlon, J. C. 2019. Understanding the evidence informing the insect apocalypse myth. EcoEvoRxiv Preprints. https://doi.org/10.32942/osf.io/2cqws

Scheper, J., M. Reemer, R. van Kats, W. A. Ozinga, G. T. J. van der Linden, J. H. J. Schaminée, H. Siepel, and D. Kleijn. 2014. Museum specimens reveal loss of pollen host plants as key factor driving wild bee decline in The Netherlands. Proceedings of the National Academy of Sciences 111:17552-17557.

Schuch, S., K. Wesche, and M. Schaefer. 2012. Long-term decline in the abundance of leafhoppers and planthoppers (Auchenorrhyncha) in Central European protected dry grasslands. Biological Conservation 149:75-83.

Shortall, C. R., A. Moore, E. Smith, M. J. Hall, I. P. Woiwod, and R. Harrington. 2009. Long-term changes in the abundance of flying insects. Insect Conservation and Diversity 2:251-260.

Simmons, B. I., A. Balmford, A. J. Bladon, A. P. Christie, A. De Palma, L. V. Dicks, J. Gallego-Zamorano, A. Johnston, P. A. Martin, A. Purvis, R. Rocha, H. S. Wauchope, C. 
F. R. Wordley, T. A. Worthington, \& T. Finch. 2019. Worldwide insect declines: An important message, but interpret with caution. Ecology and Evolution 9:3678-3680.

Simonson, W. D., H. D. Allen, \& D. A. Coomes. 2014. Applications of airborne lidar for the assessment of animal species diversity. Methods in Ecology and Evolution 5:719729.

Soga, M., and K. J. Gaston. 2018. Shifting baseline syndrome: causes, consequences, and implications. Frontiers in Ecology and the Environment 16:222-230.

Steinke, D., Breton, V., Berzitis, E., \& Hebert, P. D. (2017). The School Malaise Trap Program: coupling educational outreach with scientific discovery. PLoS biology, 15(4), e2001829.

Stork, N. 2018. How many species of insects and other terrestrial arthropods are there on Earth? Annual Review Entomology 63:31-45.

Storkey, J., A. J. Macdonald, J. R. Bell, I. M. Clark, A. S. Gregory, N. J. Hawkins, P. R. Hirsch, L. C. Todman, \& A. P. Whitmore (2016). The unique contribution of Rothamsted to ecological research at large temporal scales. In A. J. Dumbrell, R. L. Kordas, \& G. Woodward (Eds.), Advances in ecological research (Vol. 55, pp. 3-42), Chapter 1, Cambridge: MA: Academic Press.

Swengel, S. R., D. Schlicht, F. Olsen, and A. B. Swengel. 2011. Declines of prairie butterflies in the midwestern USA. Journal of Insect Conservation 15:327-339.

Tepedino, V. J., Durham, S., Cameron, S. A., \& Goodell, K. (2015). Documenting bee decline or squandering scarce resources. Conservation Biology, 29(1), 280-282.

Thomas, C. D., T. H. Jones, and S. E. Hartley. 2019. "Insectageddon”: A call for more robust data and rigorous analyses. Global Change Biology

https://doi.org/10.1111/gcb.14608

Thomas, J. A. (2005). Monitoring change in the abundance and distribution of insects using butterflies and other indicator groups. Philosophical Transactions of the Royal Society B: Biological Sciences, 360(1454), 339-357.

Tingley, M.W. 2017. Turning Oranges into Apples: Using detectability correction and bias heuristics to compare imperfectly repeated observations. In Stepping in the Same River Twice: Replication in Biological Research (A. Shavit \& A.M. Ellison, Eds.), pp. 215-233. Yale University Press.

Troudet J, Grandcolas P, Blin A, Vignes-Lebbe R \& Legendre F (2017) Taxonomic bias in biodiversity data and societal preferences. Scientific Reports 7, 9132. 
Turchin, P., A. D. Taylor, and J. D. Reeve. 1999. Dynamical Role of Predators in Population Cycles of a Forest Insect: An Experimental Test. Science 285:1068-1071.

Valtonen, A., Hirka, A., Szőcs, L., Ayres, M. P., Roininen, H., \& Csóka, G. (2017). Long-term species loss and homogenization of moth communities in Central Europe. Journal of Animal Ecology, 86(4), 730-738.

Van Dyck, H., van Strien, A. J., Maes, D., \& van Swaay, C. A. (2009). Declines in common, widespread butterflies in a landscape under intense human use. Conservation Biology, 23(4), 957-965.

Van Swaay, C.A.M., Maes, D. \& Plate, C. 1997. Monitoring butterflies in the Netherlands and Flanders: the first results. Journal of Insect Conservation 1:81-87.

Van Strien, A. J., C. A. M. van Swaay, and T. Termaat. 2013. Opportunistic citizen science data of animal species produce reliable estimates of distribution trends if analysed with occupancy models. Journal of Applied Ecology 50:1450-1458.

Van Strien, A. J., C. A. M. van Swaay, W.T.F.H. van Strien-van Liempt, M. J. M. Poot, M. F. WallisDeVries. Over a century of data reveal more than $80 \%$ decline in butterflies in the Netherlands. Biological Conservation 234:116-122.

Wagner, D. L. 2017. Trends in biodiversity: Insects. Pp. 131-143. In: D. A. DellaSala, and M. I. Goldstein (eds.), The Encyclopedia of the Anthropocene, Vol. 3, Oxford: Elsevier.

Wagner, D. L. 2019a. Global insect decline: Comments on Sánchez-Bayo and Wyckhuys (2019). Biological Conservation. 233:334-335.

Wagner, D. L. 2019b. Insect declines in the Anthropocene. Annu. Rev. Entomol. 65: In press. DOI: 10.1146/annurev-ento-011019-025151

Wepprich T, J. R. Adrion, L. Ries, J. Wiedmann, \& N. M. Haddad (2019) Butterfly abundance declines over 20 years of systematic monitoring in Ohio, USA. PLoS ONE 14(7): e0216270.

Wepprich, T. (2019). Monarch butterfly trends are sensitive to unexamined changes in museum collections over time. Proceedings of the National Academy of Sciences, 116(28), 13742-13744.

White, E. R. 2019. Minimum Time Required to Detect Population Trends: The Need for Long-Term Monitoring Programs. BioScience 69:40-46.

Willig, M. R., L. Woolbright, S. J. Presley, T. D. Schowalter, R. B. Waide, T. Heartsill Scalley, J. K. Zimmerman, G. González, and A. E. Lugo (2019). "Populations are not 
declining and food webs are not collapsing at the Luquillo Experimental Forest." Proceedings of the National Academy of Sciences 116 (25): 12143-12144.

Wolda, H. 1983. "Long-term" stability of tropical insect populations. Researches on Population Ecology 25:112-126.

Zilli, D., O. Parson, G. V. Merrett, and A. Rogers. 2014. A Hidden Markov Model-Based Acoustic Cicada Detector for Crowdsourced Smartphone Biodiversity Monitoring. Journal of Artificial Intelligence Research 51:805-827. 